\title{
PERANCANGAN SISTEM INFORMASI PENJUALAN BERBASIS WEB PADA RAMA MOTOR LAMPUNG TIMUR
}

\author{
Devi Nurhalifah ${ }^{1)}$, Mustika ${ }^{2)}$, Arif Hidayat ${ }^{3)}$ \\ Program Studi IImu Komputer, Fakultas IImu Komputer, \\ Universitas Muhammadiyah Metro
}

Jl. Gatot Subroto No.100, Yosodadi, Metro Timur, Kota Metro - Lampung

\begin{abstract}
Abstrak - Sistem informasi Penjualan dan Pembelian kendaraan merupakan suatu sistem yang memberikan layanan informasi berupa data transaksi penjualan dan pembelian barang serta stok barang. Keberadaan sistem informasi ini penting. Dalam hal ini, Showroom Rama Motor dijadikan sebagai tempat penelitian, karena sistem informasi penjualan dan pembelian kendaraan yang ada di tempat tersebut masih belum terkelola dengan baik, seperti form registrasi akun customer, tampilan katalog barang, pemesanan barang, jumlah barang yang tersedia, pembelian, bukti transaksi (pembayaran) serta tanda terima penyerahan unit kendaraan. Tujuan dari penelitian ini adalah merancang website sistem informasi penjualan berbasis web pada Rama Motor Lampung Timur. Metode penelitian yang digunakan dalam penelitian ini menggunakan metode Kualitatif. Sedangkan metode perangkat lunak adalah Waterfall dan metode pendekatan yang digunakan adalah pendekatan terstruktur. Sistem informasi ini dibangun agar dapat memberikan kemudahan dalam penjualan dan pembelian kendaraan yang dilakukan secara online.
\end{abstract}

Kata Kunci : Sistem Informasi Penjualan; Metode Waterfall; Metode Kualitatif

\begin{abstract}
Information system of Sales and Purchase vehicles is a system that provides information service including sales and purchase transaction data and stock of item. The existence of this information system is very important. In this research, Rama Motor Showroom was chosen as a place to take a research, because management information system of sales and purchase vehicles in this place is still poor, for the example are, customer account registration forms, display of item catalog, ordering of item, number of available item, purchases, proof of transaction (payment) and receipt of delivery vehicles unit. The aim of this research is to design a web-based sales information system website at Rama Motor Showroom, East Lampung. In this research, the researcher used a qualitative method. Whereas, the software method is Waterfall and the approach method uses a structured approach. This information system was made to provide convenience in sales and purchase vehicles by using internet connection (online).
\end{abstract}

Keywords: Sales Information System; Waterfall method; Qualitative Method

\section{PENDAHULUAN}

Mulyani (2017:12) menyimpulkan informasi adalah: "Data yang sudah diolah yang ditujukan untuk seseorang, organisasi ataupun siapa saja yang membutuhkan. Informasi akan menjadi berguna apabila objek yang menerima informasi yang membutuhkan informasi tersebut". 
Jenis kendaraan mobil dan motor merupakan jenis transportasi individu yang merupakan media transportasi yang paling banyak diminati. Sehingga kendaraan bukan sebagai barang mewah lagi tapi memang sudah menjadi sebuah kebutuhan masyarakat mengingat mobilitas masyarakat yang cukup tinggi.

Sistem penjualan pada Rama Motor Lampung Timur yang dilakukan secara konvensional seharusnya sudah dapat dikembangkan dengan menyesuaikan era perkembangan teknologi yang sudah berbasis web. Promosi produk yang dijual harus terintegrasi dengan sistem informasi penjualan yang dilakukan secara digital (berbasis web), tujuannya untuk melebarkan jangkauan pasar konsumen dan memberikan pelayanan maksimal kepada konsumen.

Dari penjelasan diatas, penulis merumuskan sebuah masalah yaitu "bagaimana merancang website sistem informasi penjualan berbasis web pada Rama Motor Lampung Timur?" yang bertujuan untuk merancang website sistem informasi penjualan berbasis web pada Rama Motor Lampung Timur.

\section{KAJIAN PUSTAKA DAN LANDASAN TEORI}

\section{Sistem Informasi}

Sudarmaji (2017:46) menyimpulkan sistem informasi adalah: "Suatu sinergi antara data, mesin pengolah data (yang biasanya meliputi komputer, program aplikasi jaringan) dan manusia untuk menghasilkan informasi, jadi sistem informasi bukan hanya aplikasi perangkat lunak. Sistem informasi ada pada hampir setiap perusahaan atau instansi untuk mendukung kegiatan bisnis mereka sehari-hari. Biasanya porsi pengerjaan pengembangan sistem informasi diserahkan kepada orang-orang yang bekerja dibidang teknologi informasi".

\section{Website}

Rohi Abdulloh (2018:1) menyimpulkan website adalah: "Website dapat diartikan sebagai sekumpulan halaman yang berisi informasi data digital berupa teks, gambar, animasi, suara, dan video atau gabungan semuanya yang disediakan melalui jalur koneksi internet sehingga dapat diakses dan dilihat oleh semua orang di seluruh dunia".

\section{Black Box Testing}

Ardana (2019:41) menyimpulkan Black Box Testing adalah: "Black box testing juga disebut pengujian berdasarkan fungsional atau spesifikasi. Black box ini melibatkan pengamatan terhadap output berdasarkan input tertentu. Tidak mempertimangkan detail software. Hanya diperiksa nilai output berdasarkan nilai input masing-masing. Tidak ada upaya untuk mempelajari atau memeriksa kode program bagaimana output diproduksi. Pengujian ini didasarkan pada spesifikasi eksternal. Hanya memeriksa fungsionalitas perangkat lunak, mengamati aspek-aspek dasar dari software, untuk memeriksanya apakah itu sesuai dengan kebutuhan pengguna".

\section{METODE}

Showroom Rama Motor merupakan pelopor industri penjualan sepeda motor second dan mobil second di Desa Trisnomulyo Kecamatan Batanghari Nuban Kabupaten Lampung Timur. Teknik pengumpulan data/informasi penulis menggunakan beberapa teknik yaitu: observasi, wawancara, dokumentasi dan studi literatur.

Dalam metode penulis menggunakan metode waterfall untuk proses pembuatan website. Habibi $R$ dan Karnovi $R$ (2020:31-35) menarik kesimpulan Metode "waterfall adalah suatu proses pengembangan perangkat lunak 
berurutan, dimana kemajuan dipandang sebagai terus mengalir kebawah (seperti air terjun) melewati fase-fase perencanaan, pemodelan, implementasi (konstruksi), dan pengujian. Dalam pengembangannya metode Waterfall memiliki beberapa tahapan yang runtut: requirement (analisis kebutuhan), desain sistem (System design), Coding dan Testing, Penerapan Program, pemeliharaan".

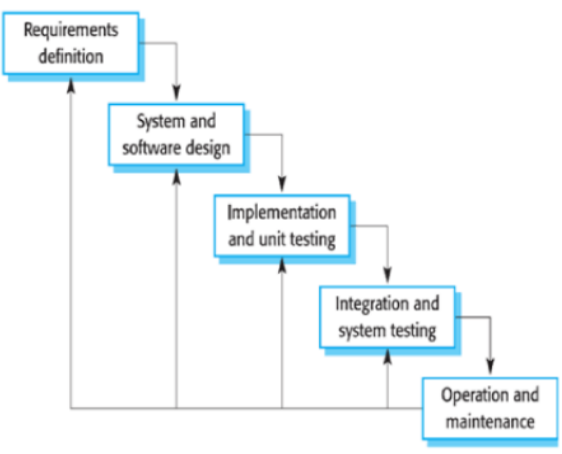

Gambar 1. Bagan Alur Metode Waterfall. (Sumber: Habibi R dan Karnovi R, 2020:31)

\section{HASIL DAN PEMBAHASAN}

Website yang dihasilkan dalam penelitian ini adalah website yang membantu Showroom Rama Motor Lampung Timur dalam melakukan promosi dan jual beli secara online.

\section{a. Relasi Tabel}
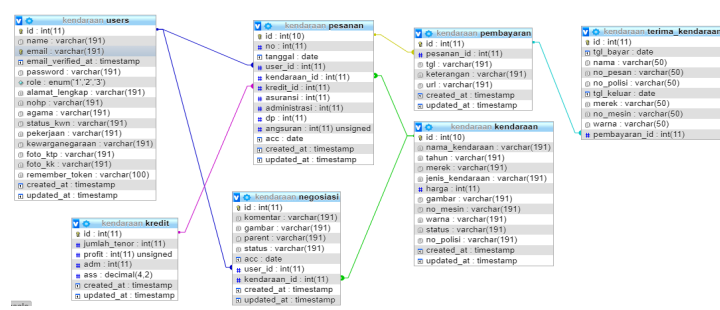

Gambar 2. Relasi Tabel

Gambar 2 merupakan gambar rancangan database website menggunakan relasi tabel. Terdapat 7 tabel yang saling berelasi yaitu user, pesanan, kendaraan, pembayaran, kredit, terima kendaraan, dan negosiasi. b. Rancangan Form Registrasi Akun Customer

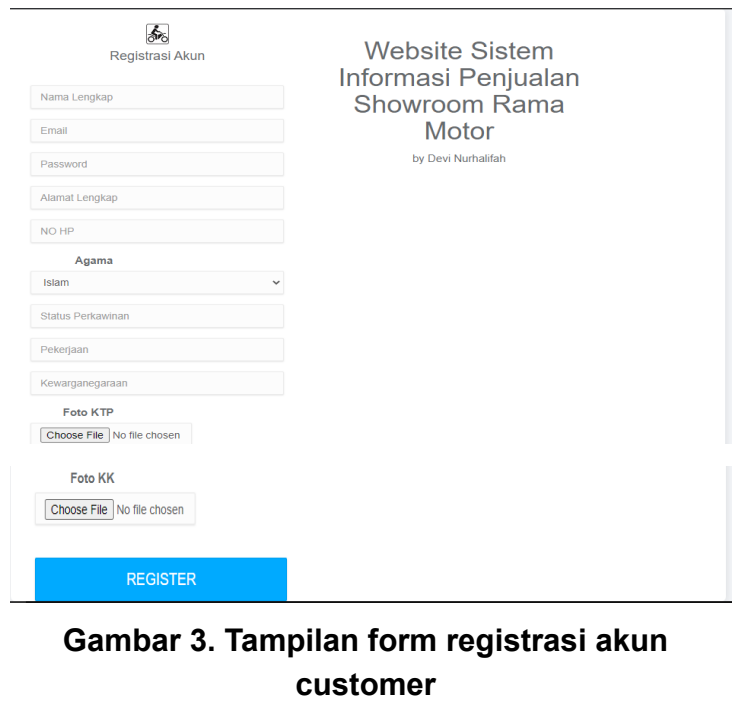

Gambar 3 merupakan gambar tampilan form registrasi akun costumer, dimana pada berbagai form tersebut dijadikan syarat untuk melakukan pembelian kendaraan.

1. Tampilan Input Produk

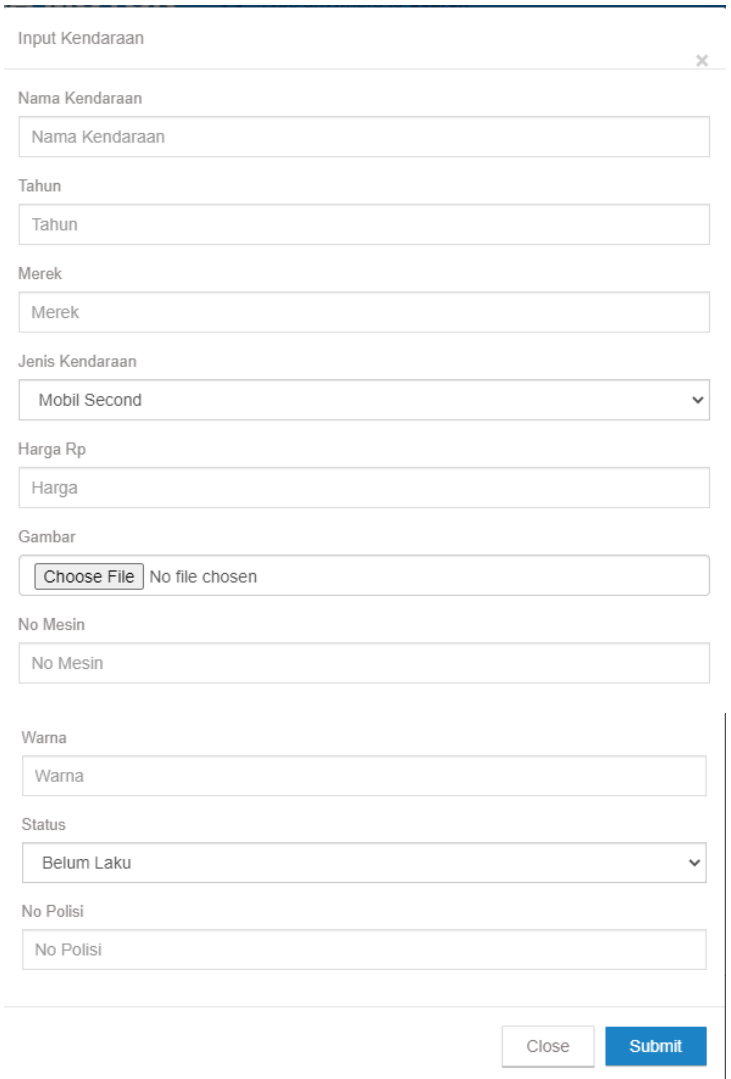

Gambar 4. Tampilan Input Produk. (Sumber. Penulis 2021) 
Gambar 4 merupakan tampilan input produk yang digunakan oleh staf marketing untuk melakukan input kendaraan yang bertujuan untuk mempromosikan kendaraan yang dijual kepada konsumen.

\section{Tampilan Katalog Barang}

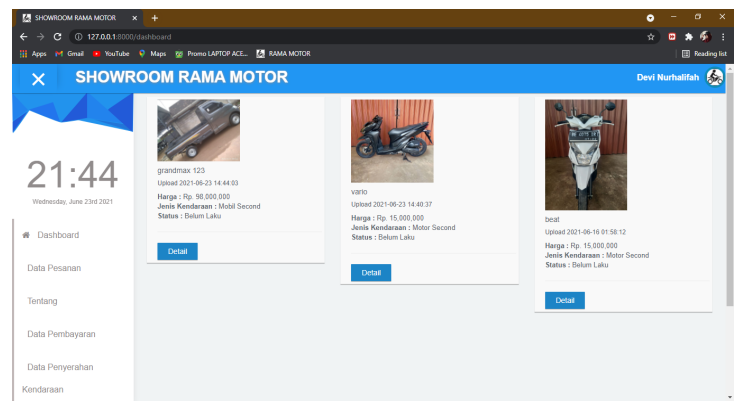

Gambar 5. Tampilan katalog barang. (Sumber. Penulis 2021)

Gambar 5 merupakan tampilan katalog barang yang sebelumnya diupload oleh staf marketing dengan input produk yang tujuannya mempromosikan kendaraan melalui website.

3. Tampilan Input Data Negosiasi

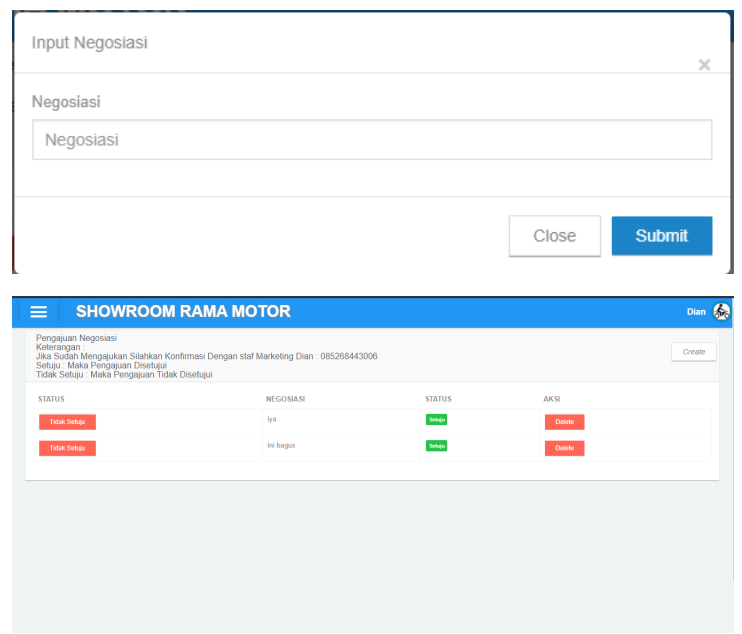

Gambar 6. Tampilan Input Data Negosiasi. (Sumber. Penulis 2021)

Gambar 6 merupakan tampilan input data negosiasi yang digunakan oleh konsumen agar dapat melakukan pengajuan negosiasi kepada Showroom Rama Motor dan jika disetujui maka staf marketing akan melakukan persetujuan dengan klik setuju, jika tidak maka klik tidak setuju.

4. Tampilan Input Data Kredit

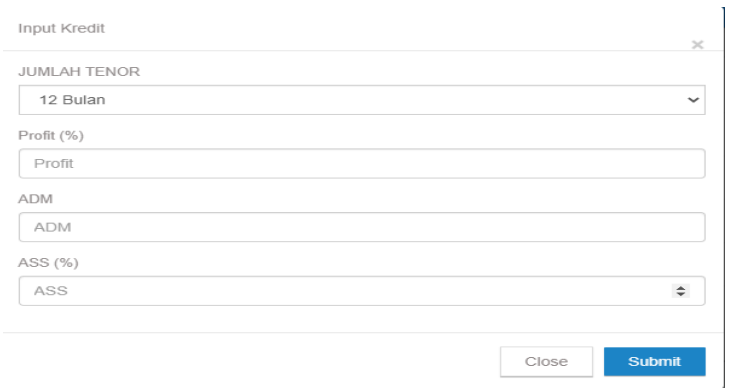

Gambar 7. Tampilan Input Data Kredit. (Sumber. Penulis 2021)

Gambar 7 merupakan tampilan input data kredit yang bertujuan untuk perhitungan jual beli yang dilakukan secara kredit oleh konsumen dan staf marketing.

5. Tampilan Pemesanan Barang
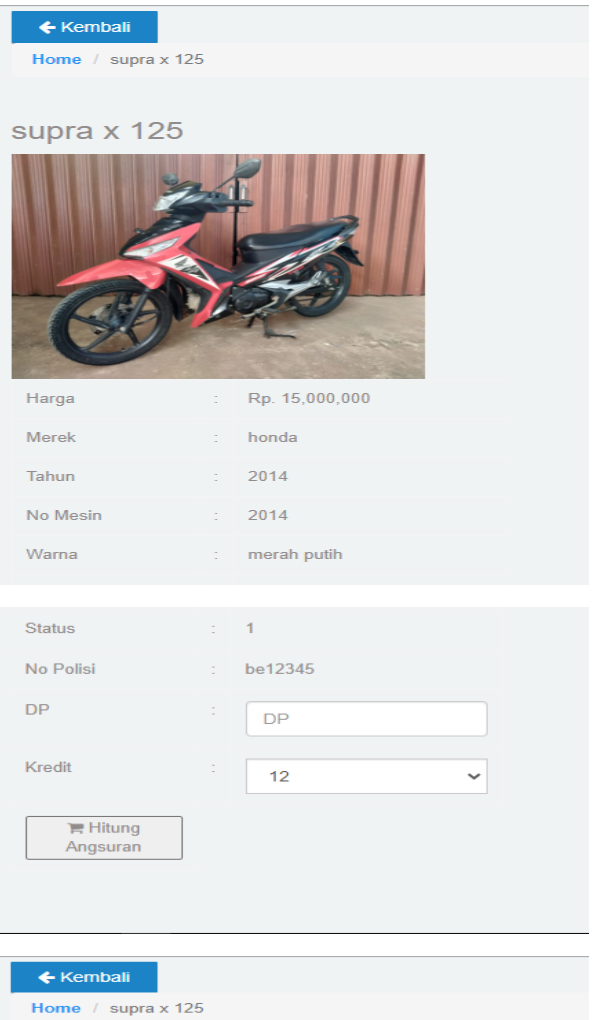

Kalkulasi Angsuran supra x 125

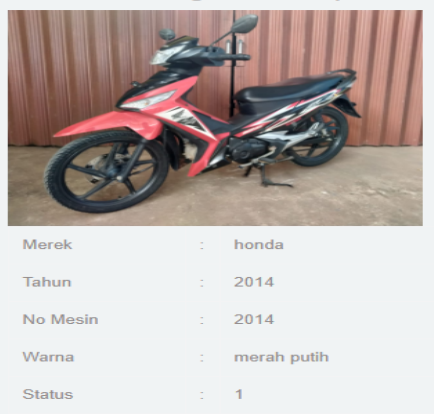




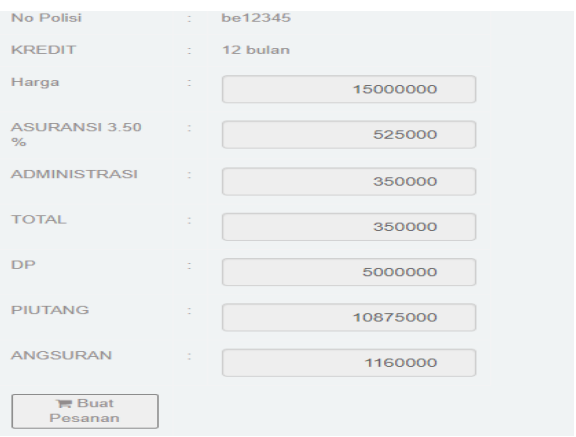

Gambar 8. Tampilan pemesanan barang. (Sumber. Penulis 2021)

Gambar 8 merupakan tampilan pemesanan barang yang digunakan konsumen dalam melakukan pemesanan barang.

6. Bukti Pembayaran

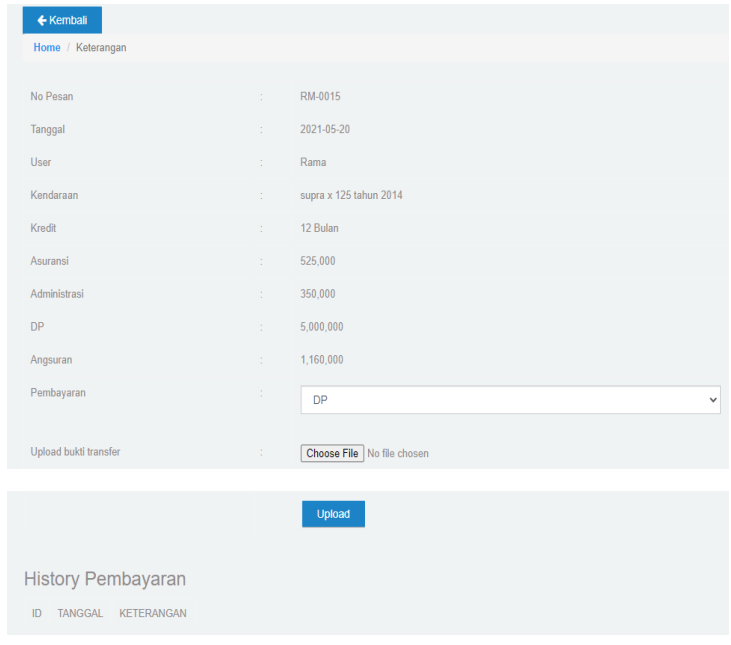

Gambar 9. Bukti Pembayaran (Sumber. Penulis 2021)

Gambar 9 merupakan tampilan input pembayaran yang dilakukan oleh konsumen sebagai bukti bahwa sudah melakukan pembayaran.

7. Tampilan Input Tanda Terima Penyerahan Unit Kendaraan

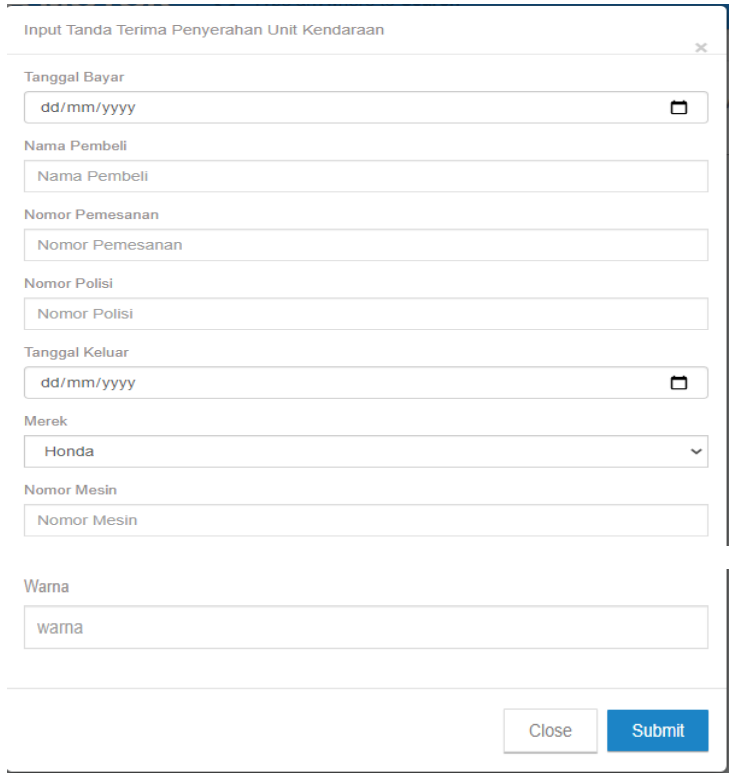

Gambar 10. Tampilan Input Tanda Terima Penyerahan Unit Kendaraan. (Sumber. Penulis 2021)

Gambar 10 merupakan tampilan input tanda terima penyerahan unit kendaraan yang digunakan oleh staf marketing dalam melakukan penginputan tanda terima yang nantinya akan diserahkan oleh konsumen sebagai bukti sudah melakukan pembelian dan akan ditandatangani kemudian akan disimpan oleh staf keuangan.

\section{KESIMPULAN}

Setelah melakukan penelitian yang dilaksanakan pada Showroom Rama Motor Lampung Timur pada tanggal 1-15 Desember 2020, dengan menggunakan metode Waterfall dan telah melakukan pengujian menggunakan Black Box Testing penulis menarik kesimpulan bahwa tujuan dari penelitian ini tercapai dimana telah dihasilkannya sebuah website sistem informasi penjualan pada Rama Motor Lampung Timur sesuai dengan tujuan dari penelitian ini yaitu perancangan sistem informasi penjualan berbasis web pada Rama Motor Lampung Timur.

Pada website sistem informasi penjualan Rama Motor yang telah dirancang oleh 
penulis ini, terdapat beberapa kelebihan yang bermanfaat bagi karyawan Rama Motor dan Konsumen Rama Motor. Kelebihan dan manfaat tersebut antara lain yaitu dengan tersedianya:

Mampu memberikan informasi jual beli kendaraan secara online dengan menampilkan katalog barang dan jumlah barang yang tersedia.

Mampu melakukan proses negosiasi, pemesanan dan pembelian barang secara online.

Mampu menginformasikan perlengkapan dokumen persyaratan pembelian secara online dan memberikan fasilitas pilihan atau menu untuk dapat meng-upload berkas persyaratan.

Memiliki kemampuan untuk melakukan pembayaran secara online dan cepat dengan melampirkan atau mengupload bukti transfer atau struk dari bank.

Mampu cetak kuitansi atau bukti transaksi, tanda terima penyerahan unit kendaraan dan dokumen lainnya secara online.

Saran untuk penulis atau peneliti selanjutnya adalah website sistem informasi penjualan Rama Motor yang telah dirancang oleh penulis ini tentunya memiliki kelemahan. Kelemahan tersebut yakni belum tersedianya fitur pemberitahuan pembelian kendaraan kepada staf marketing atau biasa disebut notifikasi di dalam website, disarankan kepada peneliti selanjutnya untuk dapat merancang sistem informasi penjualan berbasis web pada Rama Motor Lampung Timur yang bisa melengkapi fitur-fitur yang masih kurang.

\section{DAFTAR PUSTAKA}

[1] Abdulloh, R. 2018. 7 in 1

Pemrograman Web untuk Pemula. Edisi

Pertama. PT Elex Komputindo. Jakarta.

[2] Anggito, A., \& Setiawan, J.,
2018. Metodologi penelitian kualitatif. Edisi Pertama. Cetakan Pertama. CV Jejak (Jejak Publisher). Jawa Barat

[3] Ardana, I. M. S. (2020, October).

Pengujian Software Menggunakan

Metode Boundary Value Analysis dan Decision Table Testing. In ESIT (Vol. 14, No. 3, pp. 40-47). https://scholar.google.co.id/citations?vie w op=view citation\&hl=en\&user=0AvFB GsAAAAJ\&citation for view $=0$ AvFBGsA AAAJ:eQOLeE2rZwMC

[4] Anggraeni, E. Y., 2017. Pengantar Sistem Informasi. Edisi Pertama. Penerbit Andi. Yogyakarta

[5] Enterprise, J. 2015. Mengenal PHP Menggunakkan Framework Laravel. Edisi Pertama. PT Elex Media Komputindo. Jakarta.

[6] Fitria, F., \& Sudarmadi, D., 2019.

Pengaruh Sistem Informasi Akuntansi dan Pengendalian Internal terhadap Kinerja Karyawan PT. Beton Elemen Persada. JASa (Jurnal Akuntansi, Audit dan Sistem Informasi Akuntansi), 3(1), 1-13.

[7] Gerlan, AM., 2020. Aplikasi Monitoring Penelitian Dan Pengabdian Masyarakat Internal Perguruan Tinggi Menggunakan PhpMaker. Edisi Pertama. Cetakan Pertama. Penerbit Media Sains Indonesia (CV. Media Sains Indonesia). Bandung.

[8] Habibi R. dan Karnovi, R., 2020.

Tutorial Membuat Aplikasi Sistem Monitoring Terhadap Jobdesk Operational Human Capital (OHC). Edisi Pertama. Cetakan Pertama. Kreatif Industri Nusantara. Bandung.

[9] Harmayani, H dkk., 2020. E-

Commerce: Suatu Pengantar Bisnis Digital. Edisi Pertama. Cetakan Pertama. Yayasan Kita Menulis.

[10] Hendriyani, Y., dan Suryani., K., 2020. Pemrograman Android: Teori dan Aplikasi. Edisi Pertama. Cetakan 
Pertama. CV. Penerbit Qiara Media. Jawa Timur.

[11] Ibnu, MS. 2020. Otodidak Web

Programming: Membuat Website Edutainment. Edisi Pertama. PT Elex Komputindo. Jakarta.

[12] Indrawan, S.M. dan Suhartono, E., 2020. Pemrograman Dasar Pascal Untuk Penyelesaian Sains Sederhana. Cetakan Pertama. Edisi Pertama. Penerbit Lakeisha (Anggota IKAPI No. 181/JTE/2019). Jawa Tengah.

[13] Mulyani, S. (2017). Metode

Analisis dan Perancangan Sistem. Edisi Pertama. Cetakan Pertama. Abdi Sistematika. Bandung.

[14] Muharto. Dan Ambarita A. 2016.

Metode Penelitian Sistem Informasi Mengenai Kesulitan Mahasiswa dalam Menyusun Proposan Peneltian. Edisi Pertama. Cetakan Pertama. Penerbit Deepublish (Grup Penerbitan CV Budi Utama). Yogyakarta.

[15] Munthe, I. R., ST M, K., Suryadi, S., \& Kom, S. K. M., 2018. Bahasa Pemrograman Pascal. Edisi Pertama. Cetakan Pertama. Uwais Inspirasi Indonesia. Ponorogo.

[16] Pratiwi, N. I., 2017. Penggunaan Media Video Call Dalam Teknologi Komunikasi. Jurnal Ilmiah Dinamika Sosial, 1(2), 202-224.

[17] Rukajat, A., 2018. Pendekatan Penelitian Kuantitatif (Quantitative Research Approach). Edisi Pertama. Cetakan Pertama. Deepublish. Yogyakarta.

[18] Rusmawan, U., 2019. Teknik

Penulisan Tugas Akhir dan Skripsi Pemrograman. Edisi Pertama. Cetakan Pertama. PT Elex Media Komputindo. Jakarta

[19] Sudarmaji., 2018. Sisitem Informasi Manajemen. Edisi Pertama. Cetakan Pertama. Cv. Laduny Alifatama 